\title{
Incorporation of whey permeate, a dairy effluent, in ethanol fermentation to provide a zero waste solution for the dairy industry
}

\author{
Archana Parashar, ${ }^{* 1}$ Yiqiong Jin, ${ }^{* 1}$ Beth Mason, $\dagger$ Michael Chae, ${ }^{*}$ and David C. Bressler ${ }^{\star 2}$ \\ *Department of Agricultural, Food and Nutritional Science, University of Alberta, Edmonton, T6G 2P5, Canada \\ †Verschuren Centre for Sustainability in Energy \& the Environment, Cape Breton University, Sydney, B1P 6L2, Nova Scotia, Canada
}

\begin{abstract}
This study proposes a novel alternative for utilization of whey permeate, a by-product stream from the dairy industry, in wheat fermentation for ethanol production using Saccharomyces cerevisiae. Whey permeates were hydrolyzed using enzymes to release fermentable sugars. Hydrolyzed whey permeates were integrated into wheat fermentation as a co-substrate or to partially replace process water. Cold starch hydrolysis-based simultaneous saccharification and fermentation was done as per the current industrial protocol for commercial wheat-to-ethanol production. Ethanol production was not affected; ethanol yield efficiency did not change when up to $10 \%$ of process water was replaced. Lactic acid bacteria in whey permeate did not negatively affect the co-fermentation or reduce ethanol yield. Whey permeate could be effectively stored for up to $4 \mathrm{wk}$ at $4^{\circ} \mathrm{C}$ with little change in lactose and lactic acid content. Considering the global abundance and nutrient value of whey permeate, the proposed strategy could improve economics of the dairy and biofuel sectors, and reduce environmental pollution. Furthermore, our research may be applied to fermentation strategies designed to produce value-added products other than ethanol.
\end{abstract}

Key words: dairy by-product, cheese whey, whey permeate, ethanol fermentation, Saccharomyces cerevisiae

\section{INTRODUCTION}

Whey is a by-product of cheese and casein manufacturing in the dairy industry, and represents about $85 \%$ of the total milk used in the process (Panesar and

Received July 3, 2015.

Accepted October 27, 2015.

${ }^{1}$ These authors contributed equally to this work.

${ }^{2}$ Corresponding author: david.bressler@ualberta.ca
Kennedy, 2012). Lactose and protein are the major components in whey and account for approximately 75 and $10 \%$ of the TS, respectively (Mawson, 1994). Whey protein is extracted from whey by ultrafiltration. The remaining liquid, whey permeate, is composed mainly of lactose, salts, nonprotein nitrogen, and water (Jelen, 2009). Whey permeate has limited applications, and a major portion of the whey permeate produced in the world is currently being discarded as a dairy effluent. Large amounts of whey are produced annually because approximately $9 \mathrm{~kg}$ of whey is obtained per kilogram of cheese produced (Kosikowski, 1979). The world trade of whey and whey products for 2014 was estimated at 5.6 million tonnes, of which the major product was whey powder (Sossna, 2014a). Cheese manufacturing is projected to reach 25.3 million metric tonnes by 2023 (OECD-FAO, 2014), which would result in enormous amounts of available whey permeate. In 2013, the global market for whey powder and proteins was estimated at $\$ 9.8$ billion US and was forecasted to be worth $\$ 11.7$ billion US by 2017 (Sossna, 2014b). Therefore, finding novel ways to use whey permeate is crucial.

Current practices followed by the dairy industry for dealing with whey permeate include disposing of it as waste, land spreading, selling dry permeate powder, and incorporation into animal feed. The use of whey permeate as a liquid additive in livestock feed has several inherent limitations, and most importantly, this market is slowly disappearing. Although whey permeate is biodegradable, its release into the environment contributes significantly to land and water pollution due to its high biochemical oxygen demand $(40,000-48,000$ $\mathrm{mg} / \mathrm{L})$ and chemical oxygen demand (80,000-95,000 mg/L; Cotanch et al., 2006; Kushwaha et al., 2011). Effective disposal often requires extensive pretreatments and therefore contributes to the operating costs of the dairy plant (Marwaha and Kennedy, 1988). Moreover, handling large volumes of surplus whey permeate is not profitable and is a critical issue that the industry is facing. Dairy plants worldwide are currently looking 
for alternative strategies for cost-effective use of whey permeate.

The use of whey permeate as a direct lactose source has been implemented in some dairy facilities; however, this requires extensive processing, including demineralization and dewatering (Jelen, 2009). One promising avenue for direct use of whey-based lactose is in biofuel production. Several efforts have been made in the past to use whey as a fermentation substrate for ethanol production, including a few industrial-scale plants in New Zealand, United States, and Denmark (Lyons and Cunningham, 1980; USDA Rural Business and Cooperative Programs, 2008; Guimarães et al., 2010). However, low ethanol yields due to low lactose content and high process costs (such as reverse osmosis for concentrating whey) made the use of whey permeate economically unattractive and limited its widespread application. Most processes use Kluyveromyces strains to directly convert lactose to ethanol, but this genus of yeast has major drawbacks including low ethanol titers of 2.5 to $4.2 \%$ ( $\mathrm{vol} / \mathrm{vol}$ ), low osmotic tolerance, and prolonged fermentation times (USDA Rural Business and Cooperative Programs, 2008; Guimarães et al., 2010). Development of novel alternative technologies that require minimal preprocessing would not only improve overall economics for the ethanol industry, but would also create a new value-added market for this surplus dairy waste stream and reduce the environmental burden of whey permeate disposal.

One of the major problems for the ethanol industry is contamination of the fermentation process by lactic acid bacteria, which could be a primary issue associated with using whey permeate for ethanol production. It has been reported that lactic acid bacteria are the natural microorganisms present in whey (Wongso, 1993). These bacteria compete with yeast for carbon sources and produce acids that are toxic to the yeast, both of which result in decreased ethanol yields. These contamination events in industrial fermentations can result in a $27 \%$ loss in fermentation efficiency or can lead to a complete fermentation failure at the batch level (Bischoff et al., 2009). The contamination issue is becoming of greater importance as the bioethanol industry moves toward lower energy systems, including the reduction or elimination of jet cooking and lower temperature hydrolysis methods for grain feedstocks. Therefore, it is important to investigate and evaluate the potential negative effect of supplementing whey permeate containing lactic acid bacteria for ethanol production.

The aim of this study was to determine the feasibility of integrating whey permeate into the conventional grain-to-ethanol fermentation process. Specifically, we investigated if whey permeate could be used as an inexpensive co-substrate or partial process water replacement in ethanol fermentations without affecting the ethanol yield. Cold starch hydrolysis-based simultaneous saccharification and fermentation were performed using current industrial protocols for wheat-to-ethanol production. Whey permeate was procured from a large dairy producer from 2 different cheese manufacturing plants, and multiple batches were tested to validate the developed process. Saccharomyces cerevisiae, which is a favorable microorganism for industrial ethanol production, was used for fermentation due to its well-established fermentative capabilities such as high tolerance to substrate and product inhibition (Cot et al., 2007).

\section{MATERIALS AND METHODS}

\section{Materials}

Chemicals including glucose, galactose, lactic acid, and acetic acid (HPLC grade) were purchased from Sigma-Aldrich (St. Louis, MO). Sulfuric acid (HPLC grade) was acquired from Fisher Scientific (Fairlawn, NJ). The enzymes STARGEN 002 (cocktail of Aspergillus kawachii $\alpha$-amylase and Trichoderma reesei glucoamylase), Optimash TBG (thermostable $\beta$-glucanase), GC 626 (acid $\alpha$-amylase), and Fermgen (protease) were kindly provided by Genencor International (Palo Alto, CA). Viscozyme Wheat (cocktail of xylanase and pentosanase), Liquozyme SC ( $\alpha$-amylase), and Spirizyme SC DS (glucoamylase) were kindly provided by Novozymes (Franklinton, NC). Lactozyme 3000 L, a $\beta$-galactosidase from Kluyveromyces lactis, was purchased from Sigma-Aldrich (St. Louis, MO). Spring wheat (AC Andrew) was kindly provided by Seed Solutions (Viking, AB). Wheat was ground by dry-milling (grain only) using a laboratory hammer mill (model 3100, Perten Instruments, Sweden) equipped with a mill feeder (model 3170, Perten Instruments, Sweden), and sieved $(0.5 \mathrm{~mm})$ before use in fermentations. Whey permeate by-product effluent was procured in multiple batches from a large dairy producer in its liquid form (without any modifications) from 2 different Canadian cheese manufacturing plants. Saccharomyces cerevisiae, Superstart active distillers dry yeast, generously provided by Lallemand Ethanol Technology (Milwaukee, WI), was used as the fermenting organism to produce ethanol.

\section{Compositional Analyses}

Chemical profiling of the fermentation samples was done as per standard protocols. Lactose, glucose, ga- 
lactose, lactic acid, and acetic acid content was determined using an Agilent 1200 series HPLC instrument (Agilent, Santa Clara, CA), with a refractive index detector, Aminex HPX-87H column (Bio-Rad Laboratories, Hercules, $\mathrm{CA})$ at $60^{\circ} \mathrm{C}(300 \times 7.8 \mathrm{~mm})$, using 5 $\mathrm{m} M$ sulfuric acid as the mobile phase with a flow rate of $0.5 \mathrm{~mL} / \mathrm{min}$. Alternatively, for samples with less than 1 $\mathrm{g} / \mathrm{L}$ of glucose, a D-glucose kit from Megazyme (Bray, Ireland) was used; galactose content of fermentation samples was analyzed using a Megazyme Lactose/DGalactose kit. Fermentation samples were centrifuged at $15,350 \times g$ (Eppendorf 5424 centrifuge, Hamburg, Germany) for 10 min at room temperature. The supernatant was boiled for $5 \mathrm{~min}$, filtered through a $0.22-\mu \mathrm{m}$ membrane filter (Mandel Scientific, Guelph, ON), and used for analyses. Respective sugar and acid standards were used to prepare standard curves.

Ethanol content was determined using an Agilent 7890A series GC instrument (Agilent Technologies, Mississauga, ON, Canada) equipped with an Agilent 7693 series autosampler, Restek Stabilwax-DA column $(30 \mathrm{~m} \times 0.53 \mathrm{~mm}, 0.5 \mu \mathrm{m})$, and a flame ionization detector with helium as the carrier gas under a constant pressure of $51.710 \mathrm{kPa}$. Fermentation samples were centrifuged at 15,350 $\times g$ (Eppendorf 5424 centrifuge, Hamburg, Germany) for 10 min at room temperature. The supernatant was mixed thoroughly with doubledistilled water and mixed with 1\% 1-butanol, which served as the internal standard. The ratio of ethanol

Table 1. Composition of whey permeate from 2 different Canadian cheese manufacturing plants

\begin{tabular}{lcc}
\hline Composition & $\begin{array}{c}\text { Cheese } \\
\text { manufacturing } \\
\text { plant A }\end{array}$ & $\begin{array}{c}\text { Cheese } \\
\text { manufacturing } \\
\text { plant B }\end{array}$ \\
\hline DM (\%) & 23.26 & 24.0 \\
CP (\%) & 2.75 & 2.6 \\
Nonprotein N (\%) & 0.37 & 0.36 \\
Ash (\%) & 8.67 & 7.63 \\
Crude fat (\%) & 0.07 & 0.03 \\
Lactose (\%) & 81.6 & 88.1 \\
Total sugars (\%) & 82.5 & 88.7 \\
Organic acids (\%) & 6.18 & 4.1 \\
Calcium (\%) & 0.68 & 0.67 \\
Phosphorus (\%) & 0.72 & 1.12 \\
Magnesium (\%) & 0.13 & 0.17 \\
Potassium (\%) & 1.60 & 2.00 \\
Chloride (\%) & 2.04 & 1.12 \\
Sodium (\%) & 1.24 & 0.67 \\
Iron (mg/kg) & 5.31 & 45.81 \\
Copper (mg/kg) & 5.32 & 4.16 \\
Zinc (mg/kg) & 9.82 & 20.82 \\
pH & 5.54 & 5.76 \\
Density (kg/L) & 1.10 & 1.11 \\
Viscosity (cP) & 2.2 & 3.5 \\
Lactic acid bacteria ${ }^{1}(\mathrm{cfu} / \mathrm{mL})$ & $1.4-1.5 \times 10^{3}$ & $4.1-5.3 \times 10^{3}$ \\
\hline${ }^{1}$ These characteristics were determined in our laboratory, whereas the \\
suppliers provided all other information. & \\
& &
\end{tabular}

peak area to the 1-butanol peak area was used as the response factor for ethanol content calculations. Ethanol standards of $10 \%$ (vol/vol) were used to prepare standard curves. Ethanol yield efficiency was calculated as follows:

$$
\begin{gathered}
\text { ethanol yield efficiency }=[(\text { amount of ethanol/ } \\
\text { amount of fermentable sugar }) / 0.51] \times 100 \text {. }
\end{gathered}
$$

Fermentable sugar refers to glucose and galactose. The value 0.51 represents $100 \%$ theoretical ethanol yield $(0.51 \mathrm{~g}$ of ethanol $/ \mathrm{g}$ of fermentable sugar).

The total starch content of the wheat was determined using a starch assay kit obtained from Megazyme. Compositional data of the whey permeates (Table 1) were generously provided by the cheese manufacturing plants from which they were obtained. Viscosity of the whey permeate samples was measured using an Advanced Rheometer, AR 2000, TA Instruments (New Castle, DE) at room temperature using a shear rate of $10 / \mathrm{s}$ and a peak hold of 50 to $200 \mathrm{~s}$ with an average of 30 readings.

\section{Quantification of Lactic Acid Bacteria}

Fresh whey permeate samples were plated at different dilutions on plate count agar (PCA) medium to assess total bacterial content. For quantification of lactic acid bacteria specifically, whey permeate samples were also plated on Man, Rogosa and Sharpe (MRS) medium. Plates were incubated at $30^{\circ} \mathrm{C}$ for $3-5 \mathrm{~d}$, after which the viable cell count was determined and expressed as colony-forming units per milliliter. All growth experiments were done in triplicate using different batches of whey permeate.

\section{Storage Stability}

Fresh whey permeate was transferred to sterile Corning Pyrex storage bottles and stored at $4^{\circ} \mathrm{C}$ or room temperature. The $0.5-\mathrm{mL}$ samples were analyzed by HPLC (1200 series, Agilent Technologies, Santa Clara, $\mathrm{CA}$ ) at different time points (3 d, 1, 2, 3, and $4 \mathrm{wk}$ ) to determine the lactose and lactic acid content.

\section{Whey Permeate Hydrolysis}

Whey permeate was neutralized using $2 \mathrm{M} \mathrm{NaOH}$ and hydrolyzed at $30^{\circ} \mathrm{C}$ for 24 to $48 \mathrm{~h}$ at $200 \mathrm{rpm}$ using $65 \mathrm{U}$ of Lactozyme 3000L (Sigma-Aldrich) per g of lactose in the whey permeate. Hydrolyzed whey permeate was stored at $-20^{\circ} \mathrm{C}$ until further use.

Lactose hydrolysis was calculated as follows: 
Lactose hydrolysis $\%=\frac{\text { Initial }- \text { residual lactose conc. }}{\text { Initial lactose conc. }}$.

\section{Simultaneous Saccharification and Fermentation}

Cold starch hydrolysis-based simultaneous saccharification and fermentation was done as per the current industrial protocol for commercial wheat-to-ethanol production. A fermentation process using STARGEN was employed as described previously (Gibreel et al., $2009)$ with some modifications. Small-scale $(250 \mathrm{~mL})$ fermentations were done in triplicate. Briefly, wheat mash (30\% solids, wt/wt) was prepared by thoroughly mixing milled wheat with process water and the $\mathrm{pH}$ was adjusted to 4.0 using $4 \mathrm{~N} \mathrm{HCl}$. In all cases, the mash was heated in an incubator shaker (200 rpm; Innoca 44/44R, New Brunswick Scientific, Edison, NJ) to $55^{\circ} \mathrm{C}$, after which the enzymes Fermgen $(940 \mu \mathrm{L} / \mathrm{kg}$ of grain), Optimash TBG ( $80 \mu \mathrm{L} / \mathrm{kg}$ of grain), and GC $626(440 \mu \mathrm{L} / \mathrm{kg}$ of grain) were added, followed by a 1 $\mathrm{h}$ incubation with constant stirring. Diethyl pyrocarbonate $(105 \mu \mathrm{L} / \mathrm{kg}$ of mash) was added as a chemical disinfectant. STARGEN $002(2.8 \mathrm{~mL} / \mathrm{kg}$ of grain $)$ was added, and the mash was constantly mixed at $55^{\circ} \mathrm{C}$ for $1 \mathrm{~h}$ followed by the addition of urea (final concentration of $16 \mathrm{mM}$; Fisher Scientific, Ottawa, ON, Canada). The temperature of the mash was decreased to $30^{\circ} \mathrm{C}$, and hydrated $S$. cerevisiae $\left(2 \times 10^{7} \mathrm{cfu} / \mathrm{mL}\right.$ initial viable cells) was added. Fermentations were carried out in triplicate at $30^{\circ} \mathrm{C}, 200 \mathrm{rpm}$ for $72 \mathrm{~h}$. The progress and efficiencies of the fermentations were monitored by HPLC and GC. Viable yeast cell count was determined by plating samples at different time points in triplicate on Sabouraud dextrose agar medium.

\section{Integration of Whey Permeate into Wheat Fermentation for Water Replacement}

To investigate if whey permeate can be integrated into the conventional wheat fermentation process, hydrolyzed whey permeate ( $48 \mathrm{~h}$ treatment) was incorporated to replace part of the process water used for mash preparation. Cold starch hydrolysis-based simultaneous saccharification and fermentation using STARGEN was done as per the current industrial protocol for commercial wheat-to-ethanol production. Wheat mash $(30 \%$, wt/wt) was prepared and hydrolyzed whey permeate was incorporated to replace part of the process water used for mash preparation. In this study, 5, 10, 15, and $20 \%$ of the total process water was replaced by hydrolyzed whey permeate (Table 2). Saccharomyces cerevisiae was used as the fermenting organism and the fermentations were carried out for $72 \mathrm{~h}$ with $30 \%$ wheat only as the benchmark control. The progress and efficiency of the fermentations were monitored by HPLC (for sugar and organic acid contents) and GC (for ethanol content).

\section{Statistical Analyses}

All fermentations were carried out in triplicate. Results are expressed as mean \pm SD. Statistical analyses were done by ANOVA (GraphPad Software, La Jolla, $\mathrm{CA})$ and paired $t$-test for means with significance set at $P<0.05$.

\section{RESULTS AND DISCUSSION}

\section{Whey Permeate Characterization}

Whey permeates from 2 Canadian cheese manufacturing plants were employed in this study to validate the feasibility of integrating this dairy waste into the conventional wheat-to-ethanol fermentation process. The composition of whey permeates can vary depending on the milk or whey from which they were derived as well as processing practices. Based on compositional data obtained from the dairy processors, the 2 whey permeates had similar chemical compositions, though some differences were observed (Table 1). Plant B whey permeate had higher amounts of lactose, phosphorus, and minerals such as iron and zinc compared with plant A whey permeate. Conversely, whey permeate from plant B had fewer organic acids, chloride, and sodium

Table 2. Total available fermentable carbon in the fermentation groups using different amounts of hydrolyzed whey permeate (HWP) as a replacement for process water ${ }^{1}$

\begin{tabular}{lccc}
\hline $\begin{array}{l}\text { Wheat } \\
(\%)\end{array}$ & $\begin{array}{c}\text { Replacement of } \\
\text { water by HWP }(\%)\end{array}$ & $\begin{array}{c}\text { Total fermentable } \\
\text { carbon }(\mathrm{g}) \text { plant A HWP }\end{array}$ & $\begin{array}{c}\text { Total fermentable } \\
\text { carbon }(\mathrm{g}) \text { plant B HWP }\end{array}$ \\
\hline 30 & 0 & 48.97 & 48.97 \\
30 & 5 & 50.38 & 50.65 \\
30 & 10 & 51.78 & 52.33 \\
30 & 15 & 53.19 & 54.01 \\
30 & 20 & 54.60 & 55.69 \\
\hline
\end{tabular}

${ }^{1}$ Total available fermentable carbon is provided by wheat and HWP. 
than that from plant A. Whey permeate is known to contain lactic acid bacteria because it is a by-product of cheese manufacturing. Lactic acid bacteria were quantified by plating on PCA and MRS media to determine the amount of viable cells and lactic acid bacteria, respectively, that would be introduced to the fermentation system during co-blending. It was observed that plant $\mathrm{B}$ whey permeate had roughly 3 times the lactic acid bacterial content compared with plant A whey permeate (Table 1). The viscosities of both the whey permeates were measured to determine if mixing with wheat mash would influence the overall viscosity of the fermentation medium. Both whey permeates had low viscosity (Table 1), which suggested that their incorporation would likely not have a negative effect on the mixing of the fermentation medium.

\section{Stability of Whey Permeate}

A major concern associated with the use of whey permeate in its native form (as is) is its stability over time, which is also relevant from a transportation point of view. At room temperature, the lactose levels began to decrease after $1 \mathrm{wk}$ with a corresponding increase in lactic acid (Figure 1). It is known that natural microorganisms present in whey permeate would consume lactose and produce lactic acid when stored for extended periods of time (Wongso, 1993). Conversely, lactose content was relatively stable at $4^{\circ} \mathrm{C}$ over a 4 -wk period and the lactic acid concentration did not dramatically

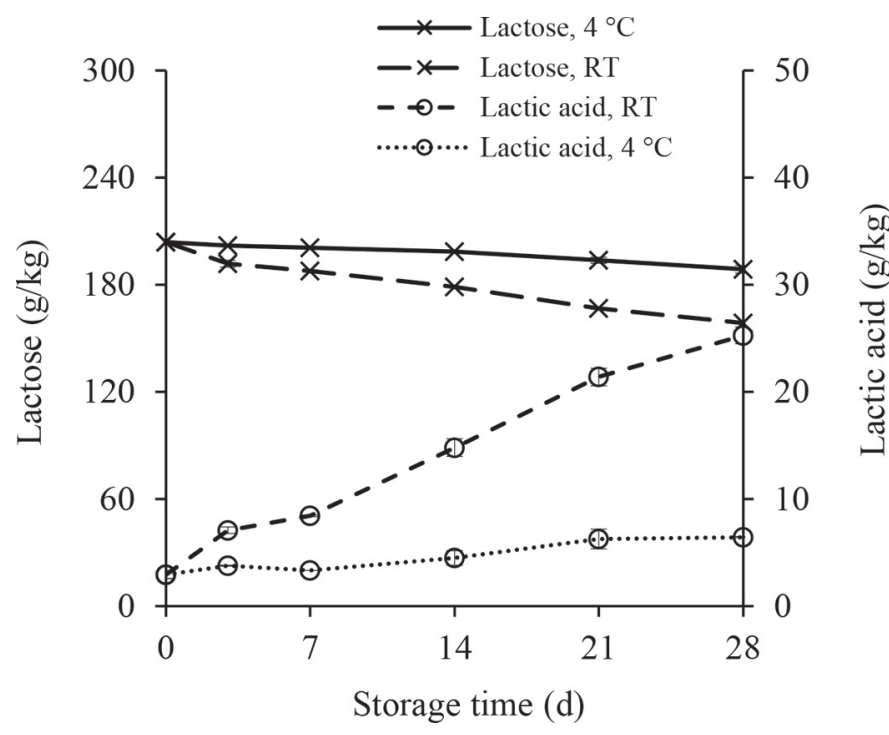

Figure 1. Concentration of lactose and lactic acid present in whey permeate stored for $28 \mathrm{~d}$ at $4^{\circ} \mathrm{C}$ or room temperature (RT). Samples were analyzed by HPLC $(\mathrm{n}=3, P<0.05)$. increase. Thus, our data demonstrate that lactic acid bacteria do not flourish in whey permeate when it is stored at $4^{\circ} \mathrm{C}$ for up to $4 \mathrm{wk}$. This result suggests that whey permeates could be transported in refrigerated tanker trucks without affecting their ability to be used as a cheap, co-fermentation substrate.

\section{Whey Permeate Hydrolysis}

Conditions for hydrolysis of lactose in the whey permeates into fermentable sugars, glucose and galactose, were optimized to obtain maximum sugar release. Whey permeate samples were routinely hydrolyzed using Lactozyme before use in co-fermentation experiments, and the sugar content was analyzed by HPLC. For plant A whey permeate, a high level of lactose hydrolysis was achieved by 8 h (93.4\%), after which no significant increase occurred at $24 \mathrm{~h}(93.6 \%)$ or $48 \mathrm{~h}(94.2 \%$; Figure $2 \mathrm{~A}$ ). On the other hand, for plant B whey permeate, lactose hydrolysis was observed to increase after $8 \mathrm{~h}$ (83.7\%) up to $24 \mathrm{~h}(92.3 \%)$, after which no significant increase was observed to occur at $48 \mathrm{~h}(92.4 \%$; Figure 2B). A difference in hydrolysis rates between the 2 whey permeates was not surprising given that they were derived from different dairy processes and contained different amounts of minerals, particularly iron and zinc, which could affect Lactozyme function. Despite the difference in their rates of hydrolysis, both permeates could be efficiently hydrolyzed to glucose and galactose and thus have the capacity for integration into fermentation processes. Furthermore, microbiological analysis of the hydrolyzed whey permeates was done by plating on PCA and MRS media. Only lactic acid bacteria were found in both whey permeates after $48 \mathrm{~h}$ of hydrolysis; 2.1 to $2.6 \times 10^{3} \mathrm{cfu} / \mathrm{mL}$ for plant A whey permeate and 6.2 to $6.8 \times 10^{3}$ for plant B whey permeate.

\section{Integration of Whey Permeate into Wheat Fermentation}

In these fermentations, ethanol yield was not affected when hydrolyzed whey permeate was incorporated to replace process water (Figure 3A). It was observed that fermentable sugars, glucose (from both wheat saccharification and hydrolyzed whey permeate) and galactose (from hydrolyzed whey permeate only), were efficiently consumed by the end of fermentation (Table $3)$. Low levels of lactic and acetic acid were produced in the medium from both fermentations, which suggested that the lactic acid bacteria present in whey permeate did not negatively affect the fermentation system. Ethanol yield efficiencies of the control and the 
fermentations using hydrolyzed whey permeate are presented in Figure 3B. Ethanol yield efficiencies were not significantly different from the control when up to $10 \%$ of the process water was replaced with whey permeate. However, replacement of $15 \%$ or higher decreased the ethanol yield efficiencies despite the increases in total fermentable carbon. This could be explained by the fact that supplementation of hydrolyzed whey permeate contributes to an increase in the initial fermentable sugar concentration in the system. It is possible that a higher initial fermentable sugar concentration has

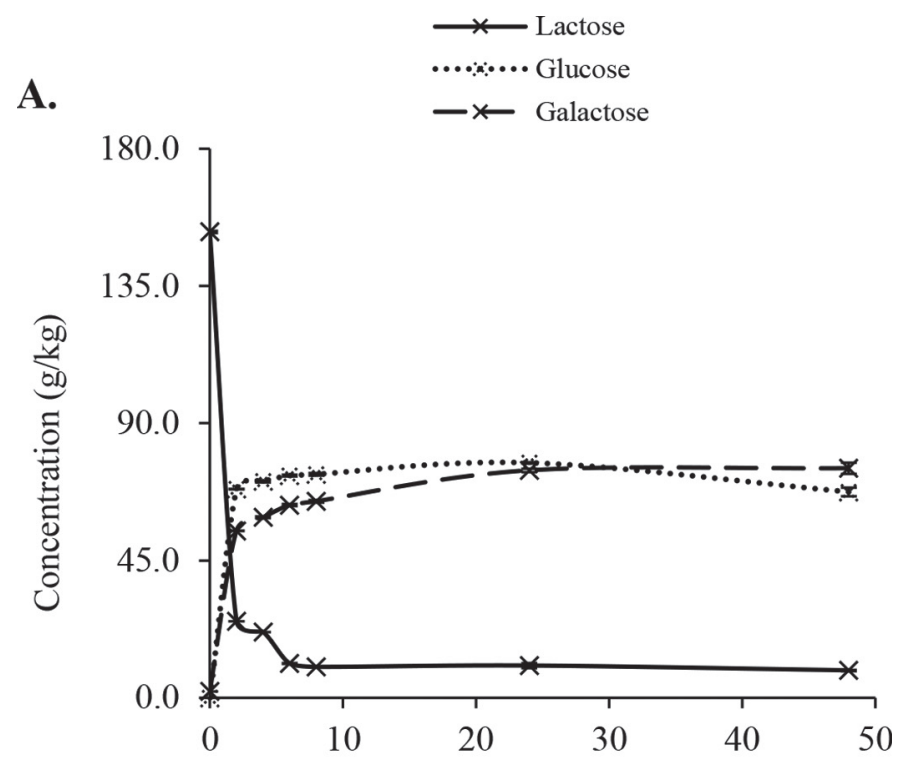

B.

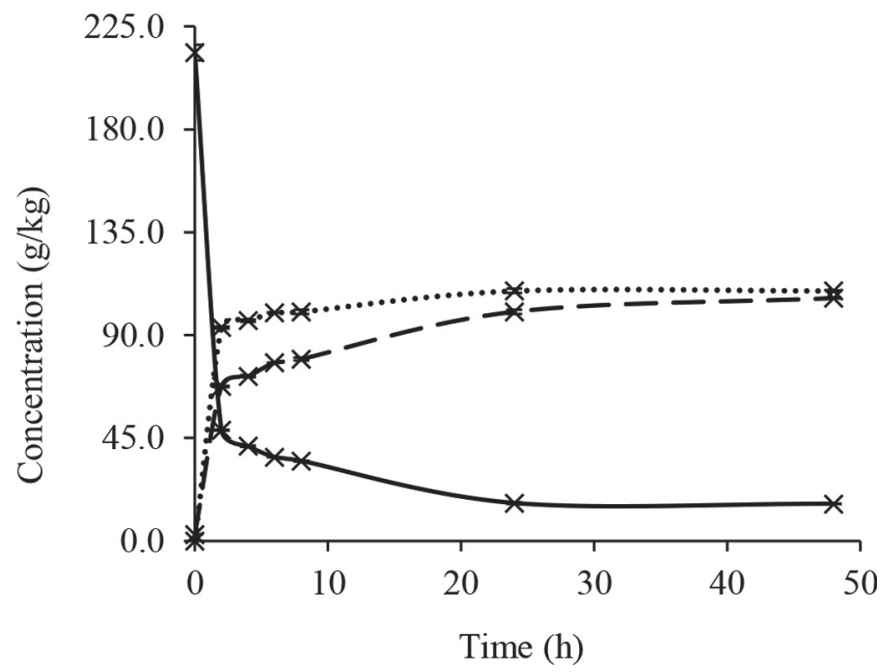

Figure 2. Concentration of lactose, glucose, and galactose during hydrolysis of whey permeate at $30^{\circ} \mathrm{C}$ for $48 \mathrm{~h}$ using Lactozyme 3000L (Sigma-Aldrich, St. Louis, MO). (A) Plant A whey permeate; (B) plant B whey permeate. $\mathrm{n}=3, P<0.05$.
A.

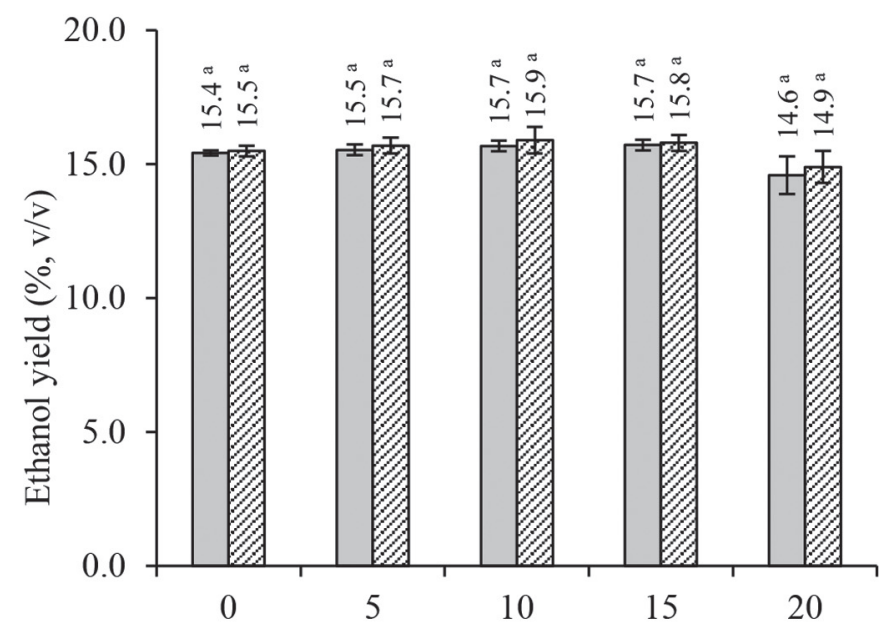

B.

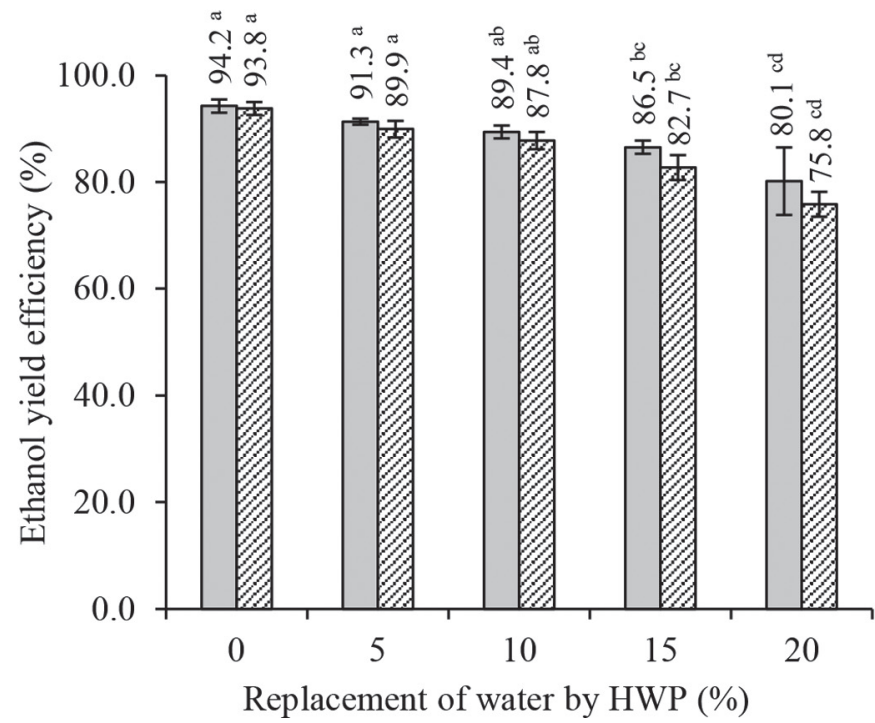

Figure 3. Ethanol production in the different fermentation groups. Fermentations were done in triplicate for $72 \mathrm{~h}$ with wheat and different amounts of hydrolyzed whey permeate (HWP) as a replacement for process water. Fermentation with $30 \%$ wheat only was the benchmark control. Ethanol concentration was determined by gas chromatography. Means with the same letter $(\mathrm{a}-\mathrm{d})$ are not significantly different $(\mathrm{n}=3, P<0.05)$. Solid bars represent plant A whey permeate, and patterned bars represent plant B whey permeate. (A) ethanol yield; (B) ethanol yield efficiency. Error bars represent SD.

an inhibitory effect on yeast as it may cause osmotic stress. Therefore, hydrolyzed whey permeate supplementation of $15 \%$ or greater was found to affect ethanol yield efficiency. Interestingly, the abundant minerals, salt content, and other minor compounds present in whey permeate did not affect the growth of yeast or negatively influence ethanol production. Furthermore, our results suggest that the proposed whey permeate 
co-blended fermentation is tolerant to differences in levels of sugar and organic acids, and thus could be adapted to accommodate a variety of whey permeates from different cheese manufacturing plants.

In previous studies when whey alone was used for ethanol production, the ethanol yield was poor (Coughlin and Charles, 1980; Moulin and Galzy, 1984). This is because when $S$. cerevisiae uses a mixture of glucose and galactose as a carbon source, diauxic growth is observed, which lowers the yield of ethanol production. However, using our proposed strategy, ethanol yield is not affected because the majority of the carbon is in the form of glucose from wheat. Whey permeate incorporation therefore works as an effective process water replacement and does not negatively affect the ethanol yield.

In addition to ethanol, dried distillers grains and solubles (DDGS) is a valuable fermentation coproduct that is used as animal feed. Profit margins of the fermentation process are improved by the nutrient value and sale of DDGS. One interesting aspect of the proposed strategy is that whey permeate incorporation into the fermentation medium provides the unique opportunity to supply additional nutrients, nitrogen, minerals, and other minor compounds that are expected to be passed on to the resulting DDGS. However, this theory requires further investigation.

\section{Effect of Lactic Acid Bacteria in Whey Permeate}

The main concern from the bioethanol industry regarding incorporation of whey permeate would be the contamination of their fermentation process by lactic acid bacteria and the possible decrease in ethanol yield. To address this concern, whey permeate was added to co-blended fermentations with or without prior filtration to remove bacterial content. The ethanol yield efficiencies of the 2 fermentations were then compared with assess the effect of lactic acid bacteria. Interestingly, no significant difference was found between ethanol yield efficiencies obtained in fermentations using filtered and nonfiltered whey permeate as 10 or $15 \%$ process water replacement (Figure 4). Lactic acid bacteria present in whey permeate therefore did not negatively affect the fermentation system by competing with yeast cells for nutrients or by reducing ethanol yield during cofermentation. Furthermore, no significant differences were found between levels of lactic acid produced in all systems in which hydrolyzed whey permeate was incorporated, regardless of whether or not it was filtered (Table 4). These results suggest that hydrolyzed whey permeate can be incorporated into wheat fermentations as is without further treatment to remove lactic acid bacteria. 


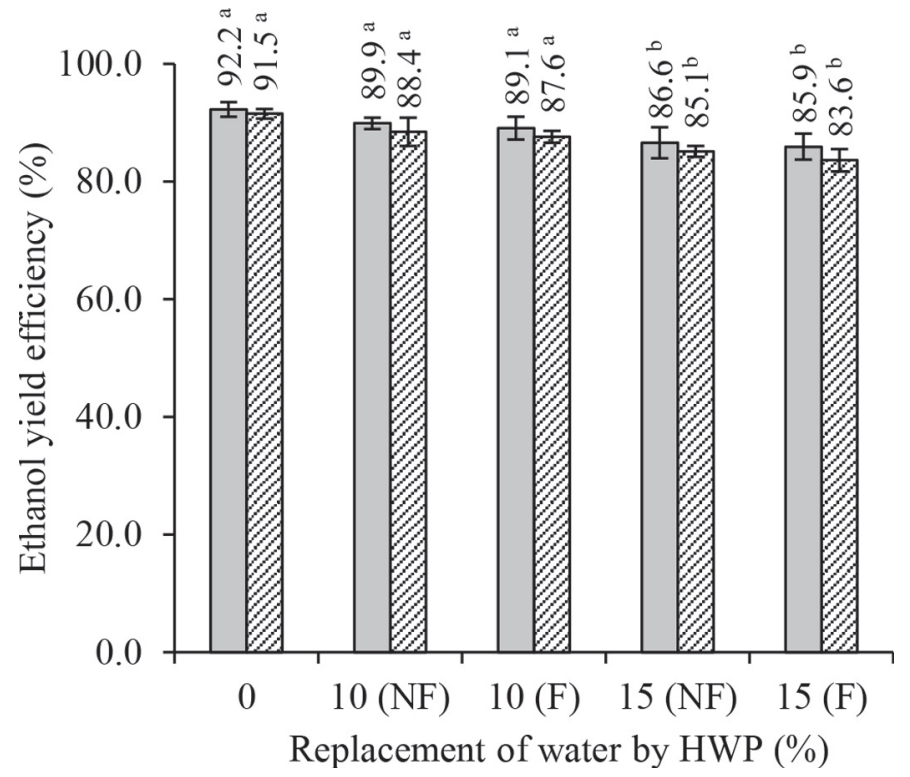

Figure 4. Ethanol yield efficiencies of fermentations using filtered or nonfiltered hydrolyzed whey permeate (HWP). Fermentations were done in triplicate for $72 \mathrm{~h}$ with wheat and different amounts of HWP as a replacement for process water. Fermentation with $30 \%$ wheat only was the benchmark control. Nonfiltered (NF) and filtered (F) HWP were used, and ethanol concentrations were assessed using gas chromatography. Means with the same letter $(\mathrm{a}, \mathrm{b})$ are not significantly different (n $=3, P<0.05)$. Solid bars represent plant A whey permeate, and patterned bars represent plant B whey permeate. Error bars represent SD.

\section{CONCLUSIONS}

This work successfully demonstrated the use of whey permeate, a consistent and readily available dairy byproduct effluent stream, as a process water replacement and co-substrate in wheat-to-ethanol fermentations. The abundant mineral and salt content of the whey permeate did not negatively influence ethanol production when co-blended with wheat. To our knowledge, this is the first study to demonstrate the potential of integrating whey permeate dairy waste into grain fermentation. In 2013, Canadian ethanol production reached 1.730 billion liters per year (USDA Foreign Agricultural Service, 2014). The scope for the proposed strategy is huge as it may be possible to apply it to feedstocks other than wheat, such as corn. This research will potentially benefit both the dairy and ethanol industries. Benefits to the dairy industry could possibly include value addition to their by-product stream, improved economics, and minimization of waste, whereas benefits to the ethanol industry may include reduction of fresh water demands, potentially enhanced DDGS by-product, and improved overall economics. The key to using this globally abundant by-product dairy waste stream is to change the perception of whey permeate as a waste

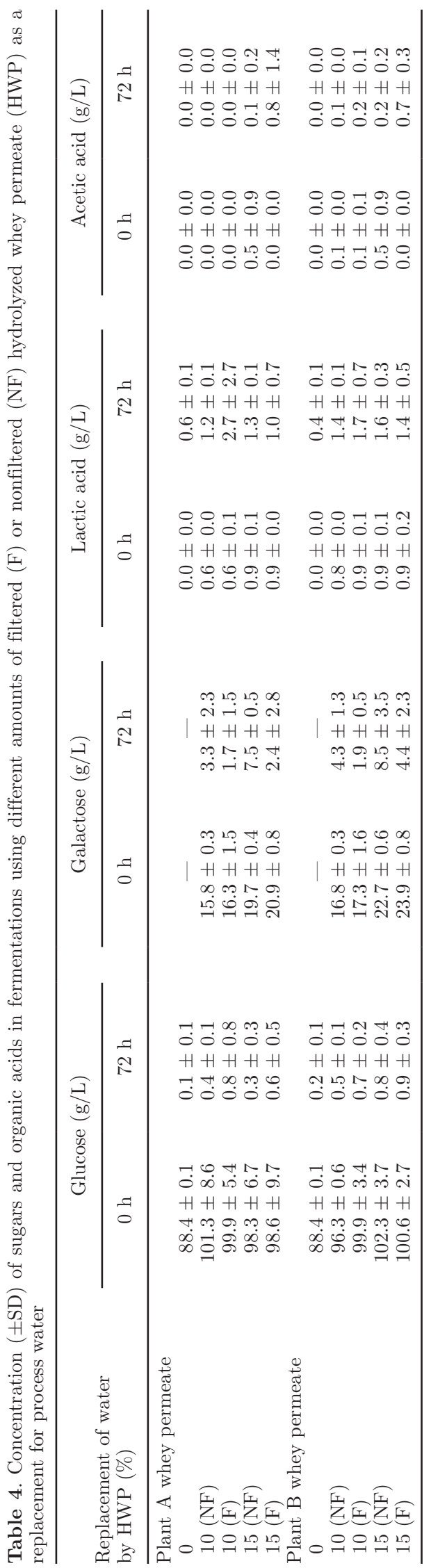


material to an opportunity to improve economics, and more importantly, to reduce environmental pollution.

\section{ACKNOWLEDGMENTS}

This work was supported by the Alberta Livestock and Meat Agency (ALMA, Edmonton, AB, Canada) and The Natural Sciences and Engineering Research Council of Canada (NSERC). We thank Genencor International (Palo Alto, CA) for supplying enzymes, Seed Solutions (Viking, AB, Canada) for providing wheat, and Lallemand Ethanol Technology (Milwaukee, WI) for donating SuperStart distillers yeast.

\section{REFERENCES}

Bischoff, K. M., S. Liu, T. D. Leathers, R. E. Worthington, and J. O. Rich. 2009. Modeling bacterial contamination of fuel ethanol fermentation. Biotechnol. Bioeng. 103:117-122.

Cot, M., M. O. Loret, J. Francois, and L. Benbadis. 2007. Physiological behaviour of Saccharomyces cerevisiae in aerated fed-batch fermentation for high level production of bioethanol. FEMS Yeast Res. 7:22-32.

Cotanch, K. W., J. W. Darrah, T. K. Miller Webster, and W. H. Hoover. 2006. The effect of feeding lactose in the form of whey permeate on the productivity of lactating dairy cattle. Accessed Jun. 8, 2015. http://www.whminer.com/research/whm-06-1.pdf.

Coughlin, R. W., and M. Charles. 1980. Applications of lactase and immobilized lactase. Pages 153-173 in Immobilized Enzymes in Food Processing. W. H. Pitcher, ed. CRC Press Inc., Boca Raton, FL.

Gibreel, A., J. R. Sandercock, J. Lan, L. A. Goonewardene, R. T. Zijlstra, J. M. Curtis, and D. C. Bressler. 2009. Fermentation of barley by using Saccharomyces cerevisiae: Examination of barley as a feedstock for bioethanol production and value-added products. Appl. Environ. Microbiol. 75:1363-1372.
Guimarães, P. M., J. A. Teixeira, and L. Domingues. 2010. Fermentation of lactose to bio-ethanol by yeasts as part of integrated solutions for the valorisation of cheese whey. Biotechnol. Adv. $28: 375-384$.

Jelen, P. 2009. Dried whey, whey proteins, lactose and lactose derivative products. Pages 255-267 in Dairy Powders and Concentrated Products. A. Y. Tamime, ed. Wiley-Blackwell, Oxford, UK.

Kosikowski, F. V. 1979. Whey utilization and whey products. J. Dairy Sci. 62:1149-1160.

Kushwaha, J. P., V. C. Srivastava, and I. D. Mall. 2011. An overview of various technologies for the treatment of dairy wastewaters. Crit. Rev. Food Sci. Nutr. 51:442-452.

Lyons, T. P., and J. D. Cunningham. 1980. Fuel alcohol from whey. Am. Dairy Rev. 42:42A-42E.

Marwaha, S. S., and J. F. Kennedy. 1988. Whey-Pollution problem and potential utilization. Int. J. Food Sci. Technol. 23:323-336.

Mawson, A. J. 1994. Bioconversions for whey utilization and waste abatement. Bioresour. Technol. 47:195-203.

Moulin, G., and P. Galzy. 1984. Whey, a potential substrate for biotechnology. Biotechnol. Genet. Eng. Rev. 1:347-374.

OECD-FAO (Organization for Economic Co-operation and Development, Food and Agriculture Organization of the United Nations). 2014. OECD-FAO Agricultural Outlook 2014-2023: Dairy. Accessed Jun. 16, 2015. http://www.oecd-ilibrary.org/ agriculture-and-food/oecd-fao-agricultural-outlook-2014_agr_ outlook-2014-en.

Panesar, P. S., and J. F. Kennedy. 2012. Biotechnological approaches for the value addition of whey. Crit. Rev. Biotechnol. 32:327-348.

Sossna, R. 2014a. The world of whey got together: 7th International Whey Conference. International Dairy Magazine. 10:22-23.

Sossna, R. 2014b. 3A Business Consulting: WHEY BOOK 2014. Int. Dairy Mag. 10:20-21.

USDA Foreign Agricultural Service. 2014. Biofuels Annual 2014Canada. Accessed Jun. 8, 2015. http://gain.fas.usda.gov/ Recent\%20GAIN\%20Publications/Biofuels\%20Annual_Ottawa_ Canada_11-24-2014.pdf.

USDA Rural Business and Cooperative Programs. 2008. Research Report 214: Whey to ethanol: A biofuel role for dairy cooperatives? Accessed Jun. 8, 2015. http://www.rd.usda.gov/files/RR214.pdf.

Wongso, D. D. 1993. Optimization of industrial whey ethanol fermentation process. Doctoral dissertation, Massey University, Palmerston North, New Zealand. 